\title{
loT solution for monitoring indoor climate parameters in open space offices
}

\author{
Ioana Udrea $^{1, *}$, Viorel Ionut Gheorghe ${ }^{1}$, Laurentiu Adrian Cartal $^{1}$, Despina Duminica ${ }^{1}$, \\ Silviu Petrache ${ }^{1}$, Tudor Catalin Apostolescu ${ }^{2}$, and Valeru Friedemann Kraus ${ }^{3}$ \\ ${ }^{1}$ Mechatronics and Precision Mechanics Department, Faculty of Mechanical Engineering and \\ Mechatronics, University "POLITEHNICA" of Bucharest, RO \\ ${ }^{2}$ Faculty of Informatics, Titu Maiorescu University, Bucharest, RO \\ ${ }^{3}$ ARCHIBUS Solution Center - Romania, Bucharest, RO
}

\begin{abstract}
Although there are numerous high performance BMS (Building Management System), which monitor the indoor climate parameters, data access, sensor positioning, and other aspects may not be under control. On the other hand, IoT (Internet of Things) is experiencing exponential growth, as more and more devices and sensors are connected to the cloud. Thus, a sensor monitoring solution for indoor climate parameters was developed. The proposed solution is not expensive, and it is based on a Raspberry Pi board endowed with temperature, humidity, and pressure sensors. The developed application reads the values detected by the sensors, processes the date, and afterwards transmit the information to the IoT ThingSpeak platform. The large area is characteristic of open space offices, so the influence of radiant walls is small, and the operative temperature can be approximate with air temperature. This type of building is conditioned by the air conditioning system, so the air speed in this indoor environment is usually low and could be approximated by the design. So, with the data read by the developed solution the thermal comfort parameters can be approximated. If inadequate values are found, teams that carry out complex and precise measurements could be sent to the site. To achieve this goal a PMV calculator software is developed. Its validity is tested in accordance with the European standard ISO 7730. After that, the PMV computer is used with data read from sensors. Both the data read from the sensors and the newly calculated PMV are sent to the ThingSpeak IoT platform.
\end{abstract}

\section{Introduction}

The Internet of Things (IoT) is growing exponentially and it is considered by many as the most important technology initiative of today [1]. The main objective of IoT based environment monitoring system is to provide environmental parameters at remote location

\footnotetext{
*Corresponding author: ioana.udrea@upb.ro, udreaioana@yahoo.com
} 
using internet. The IoT does not function without cloud-based applications to interpret and transmit the data coming from multiple sensors. The IoT solution provides the possibility of logging measurements from locations all over the world and of visualizing and analyzing the gathered data from any device connected to the Internet [2].

Among the most popular publicly available IoT platforms, which collect data from sensors used in countless fields including heating, ventilation, and air conditioning (HVAC), indoor air quality (IAQ) and thermal comfort (TC), are the following: Thingwork, SensorCloud, RealTime.io, OnePlatform [3].

Another aspect to be considered in sensors monitoring is represented by the way in which the sensors communicate the data. Among the technologies available in IoT, RFID and sensor networks are considered the fastest growing information and communication technologies [4]. A comparison between four different communication technologies, NFC, RFID, Bluetooth and Wi-Fi is done in [2], the authors concluded that low-power Wi-Fi promises multiple years of battery lifetime while providing easy integration to existing infrastructure with built-in IP-network compatibility.

In modern buildings management systems (BMS) are used. The most intelligent systems integrate various sensors such as temperature, humidity, lighting level, $\mathrm{CO} 2$ and others. Currently most of the data are analyzed directly by the BMS software or at most related to the building information model (BIM) [5].

An important human thermal comfort index, that take into account thermal indoor parameters that could be read by the sensors, is predicted mean vote (PMV). The PMV model is developed by professor Fanger [6] and its work is considered as classical model of thermal comfort. It considers that human comfort depends on the quantitative, combined influence of six parameters (air temperature, mean radiant temperature, water vapor pressure, air velocity, clothing level, and metabolic rate).

Measurement of thermal comfort parameters inside a building could be done using performant devices, like ComfortSense [7]. The device can use high-performance probes for measuring the operating temperature, relative humidity, air temperature, and velocity [8]. ComfortSense consists of a main frame with a built-in A/D (analog/digital) converter and USB 2.0 interface. The measurement probes, connected with the main frame, are positioned on the system stand, a tripod. The measurement is set up using a PC and application software. If you want real time data from multiple locations, ConfortSense cannot be used. Once due to the fact that the application it has does not have an API with which to transmit data on an IoT platform (probably this was not wanted because such systems are not intended to work without stopping). The second reason would be the high costs of the device, because to transmit simultaneously from several rooms would require a system for each of them.

For this reason, this paper is proposed to develop a less expensive solution that is suitable for IoT. It involves reading the thermal comfort parameters using a sensor system connected on a Raspberry Pi device and transmitting the read values in real time to an IoT platform. At the same time, based on these parameters, the PMV thermal comfort index will be calculated and published in real time on the chosen IoT platform.

Some of the parameters that are part of the PMV index will be approximated. For a better approximation it is recommended that the system be used in the central area of an open space office, where the influence of the radiant temperature of the outer elements of the building envelope is very small.

Due to the approximations it introduces, this solution is not thought of as a precise solution for calculating PMV, it is thought of as an indicator of places where comfort problems could occur. In these places, teams could be sent later to make precise measurements of the comfort parameters. The main advantage of the solution proposed in this paper is that the IoT solution can centralize data from many sensor systems and identify in real time, the zones with potential problems in a wide area. 


\section{Method and procedure}

\subsection{Sensor system presentation and ThingSpeak platform}

The sensor system used in this study is composed of a Raspberry Pi board, a multiplexing connection board and a breadboard with two sensors module DHT22 (composed of a temperature and a humidity sensor) [9] and BMP180 [10] (compose of a temperature and a humidity sensor). In order to facilitate the Raspberry Pi connection with the two sensors and the fan, a multiplexing board is used, see fig. 1.

The Raspberry Pi used is a Model 4, B [11]. It is a credit-card-sized single-board computer. The CPU on the board is an ARM v8 processor with $1.5 \mathrm{GHz}$ speed. It has a variety of interfacing peripherals, including 2 USB 3.0 ports, 2 USB 2.0 ports, 2 micro-HDMI ports, 4 GB RAM, Micro-SD Card storage and 40 pin GPIO header. For GPIO port expansion a multiplexing connection board is used.

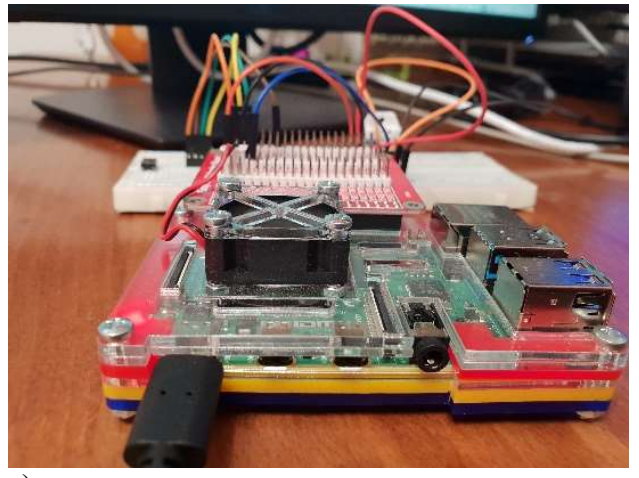

a)

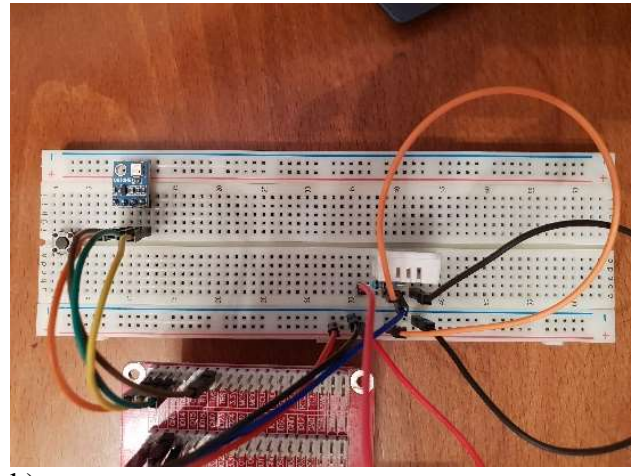

b)

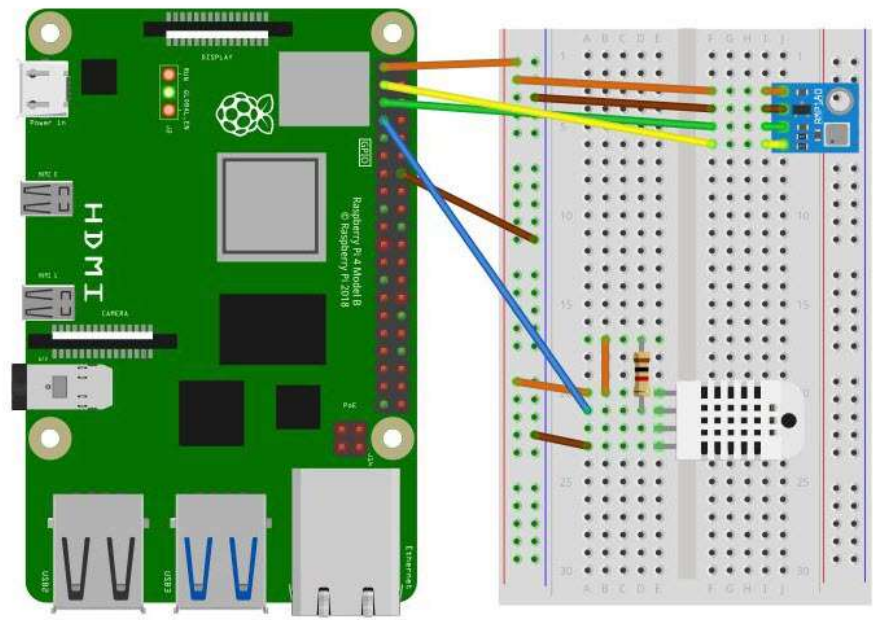

c)

Fig. 1. Sensor system: a) photo - all components: Raspberry Pi, multiplexing board, breadboard with sensors; b) photo - detail of sensor's area; c) schematic representation of the system. 
Two monitors, keyboard, and mouse can be connected to Raspberry Pi through micro-HDMI and USB connectors and it can be used like a desktop computer. It supports a number of operating systems including a Debian-based Linux distro, Raspbian, which is used in our design. Raspberry Pi can be connected to a local area network through Ethernet cable or USB Wi-Fi adapter, and then it can be accessed through SSH remote login.

Additionally, the Raspberry Pi is equipped with a housing and a $5 \mathrm{~V}$ fan.

In figure 1.c) schematic representation of the system is presented, one can see the connections that are made between the Raspberry Pi board with the DHT22 sensor and with the BMP180 sensor. The diagrams were made using Fritzing software.

ThingSpeak [12] is an IoT analytics platform service that allows in an easy way to aggregate, visualize, and analyse live data streams in the cloud. One can send data to ThingSpeak from his devices, create instant visualization of live data, and send alerts.

\subsection{PMV equation in the classical approach of thermal comfort}

The equations for PMV index, established by Fanger in his doctoral thesis [6], are used in the European standard ISO-7330 [13], see equation (1) to (4) of this standard. A clear explanation of the terms involved in the expression PMV can be found in equation (2.1) of Webb [14], the formula taken also in equation (1) of this paper.

$$
\begin{aligned}
& P M V=\underbrace{\left[0.303 \cdot e^{(-0.036 \cdot M)}+0.028\right]}_{\text {thermal sensation coefficient }} . \\
& \cdot\{\underbrace{(M-W)}_{\text {internal heat production }} \\
& \underbrace{-3.05 \cdot 10^{-3} \cdot\left[5733-6.99 \cdot(M-W)-p_{a}\right]}_{\text {heat loss trough skin }} \\
& \underbrace{-0.42 \cdot[(M-W)-58.15]}_{\text {heat loss by sweating }} \\
& \underbrace{-1.7 \cdot 10^{-5} \cdot M \cdot\left(5867-p_{a}\right)}_{\text {latent respiration heat loss }} \\
& \underbrace{-0.0014 \cdot M \cdot\left(34-t_{a}\right)}_{\text {dry respiration heat loss }} \\
& \underbrace{\left.-3.96 \cdot 10^{-8} \cdot f_{c l} \cdot\left[\left(t_{c l}+273\right)^{4}-\left(\overline{t_{r}}+273\right)^{4}\right)\right]}_{\text {heat loss by radiation }} \\
& \underbrace{+f_{c l} \cdot h_{c} \cdot\left(t_{c l}-t_{a}\right)}_{\text {term description below }}\} \\
& \begin{array}{c}
t_{c l}=35.7-0.028 \cdot(M-W)-I_{c l} \cdot\left\{3 . 9 6 \cdot 1 0 ^ { - 8 } \cdot f _ { c l } \cdot \left[\left(t_{c l}+273\right)^{4}-\right.\right. \\
\left.\left.\left(\bar{t}_{r}+273\right)^{4}\right]+f_{c l} \cdot h_{c} \cdot\left(t_{c l}-t_{a}\right)\right\}
\end{array} \\
& h_{c}= \begin{cases}2.38 \cdot\left|t_{c l}-t_{a}\right|^{0.25} \text { for } 2.38 \cdot\left|t_{c l}-t_{a}\right|^{0.25}>12.1 \cdot \sqrt{v_{a r}} \\
12.1 \cdot \sqrt{v_{a r}} & \text { for } 2.38 \cdot\left|t_{c l}-t_{a}\right|^{0.25}<12.1 \cdot \sqrt{v_{a r}}\end{cases}
\end{aligned}
$$




$$
f_{c l}=\left\{\begin{array}{c}
1.00+1.290 \cdot I_{c l} \text { for } I_{c l} \leq 0.078 \mathrm{~m}^{2} \mathrm{~K} / W \\
1.05+0.645 \cdot I_{c l} \text { for } I_{c l}>0.078 \mathrm{~m}^{2} \mathrm{~K} / W
\end{array}\right.
$$

where,

$\mathrm{M}-$ metabolic rate $\left[\mathrm{W} / \mathrm{m}^{2}\right]$;

$\mathrm{W}$ - effective mechanical power $\left[\mathrm{W} / \mathrm{m}^{2}\right]$;

$\mathrm{I}_{\mathrm{cl}}$ - clothing insulation $\left[\mathrm{m}^{2} \mathrm{~K} / \mathrm{W}\right]$;

$\mathrm{f}_{\mathrm{cl}}$ - clothing surface area factor;

$\mathrm{t}_{\mathrm{a}}$ - air temperature $\left[{ }^{\circ} \mathrm{C}\right]$;

$\overline{\mathrm{t}_{\mathrm{r}}}$ - mean radiant temperature $\left[{ }^{\circ} \mathrm{C}\right]$;

$\mathrm{v}_{\mathrm{ar}}$ - relative air velocity $[\mathrm{m} / \mathrm{s}]$;

$\mathrm{p}_{\mathrm{a}}$ - water vapour partial pressure $[\mathrm{Pa}]$;

$\mathrm{h}_{\mathrm{c}}-$ convective heat transfer coefficient $\left[\mathrm{W} /\left(\mathrm{m}^{2} \mathrm{~K}\right]\right.$;

$\mathrm{t}_{\mathrm{cl}}$ - clothing surface temperature $\left[{ }^{\circ} \mathrm{C}\right]$.

In ISO 7730 [13], Annex D, is presented a basic computer program for calculating PMV and PPD. In this program, the four-degree equation of $t_{c l}$ is solved by iterations.

The ISO 7330 standard declares that the basic computer software for calculating PMV and PPD given it's just a recommendation, other programming languages may also be used. The output should be verified with the example values given in Table D.1 from this standard.

Regarding the PMV equation, this paper aims two things. The first to perform in Python a function that can be called with all the parameters included in the PMV calculation, in this sense the steps in Annex D of the standard will be followed, this is presented in chap. 3.2. After testing, the function will be used by software that reads data from sensors, chap. 3.1. Here some parameters can still be set and others (temperature, humidity) are read from the sensors. Chapter 4. shows how to use the software and specifies all the values we used as input data for calculate PMV.

\section{Software development}

\subsection{Sensor system integration in ThingSpeak}

Raspberry Pi4 operating system (Raspbian, from Unix/Linux OS family [15]) - Raspbian comes pre-installed with plenty of software for education, programming, and general use. It has Python, Scratch, Sonic Pi, Java and more. A special developed Python script runs on this Linux system.

First a ThingSpeak account was settled and afterwards a new Channel on ThingSpeak was defined and configured. A Channel is used to collect data from a device, from another channel, or from the web. Each channel includes eight fields that can hold any type of data, plus three fields for location data and one for status data.

In fig. 2 one can see the details of new defined Channel, named DHT22\&BMP180_RaspberryP $i$, that is used for showing the data received from sensors and some computed data (PMV value, the calculation of which will be presented in the next subchapter). For each to be shown, a field was defined, thus appearing the fields named: Temperature DHT22 [ $\left.{ }^{\circ} \mathrm{C}\right]$, Humidity DHT22 [\%], Temperature BMP180 [ $\left.{ }^{\circ} \mathrm{C}\right]$, Pressure BMP180 [mBar], PMV. 


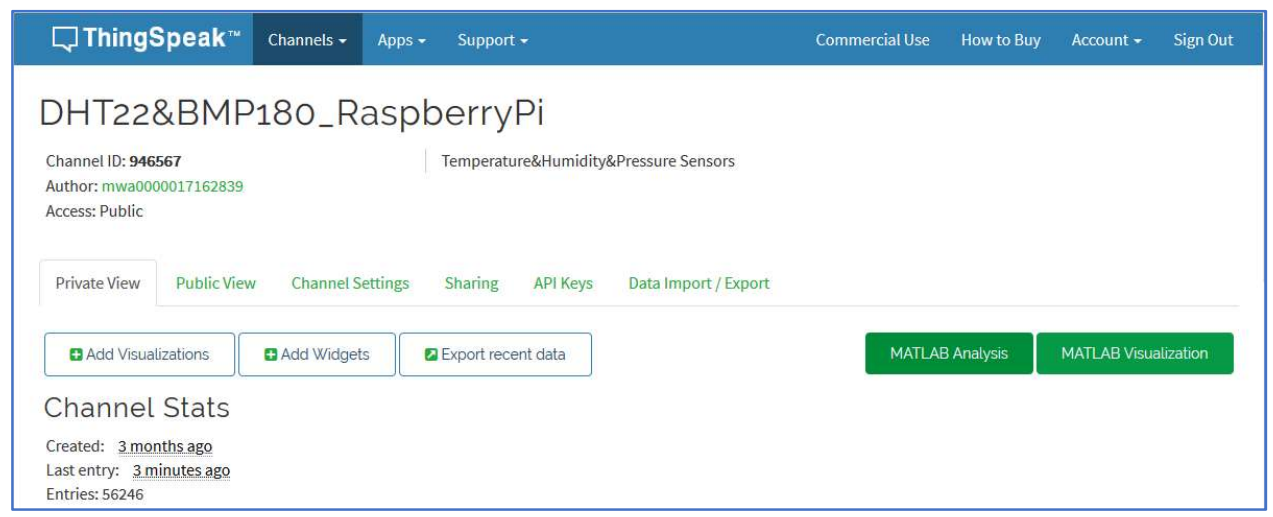

a)

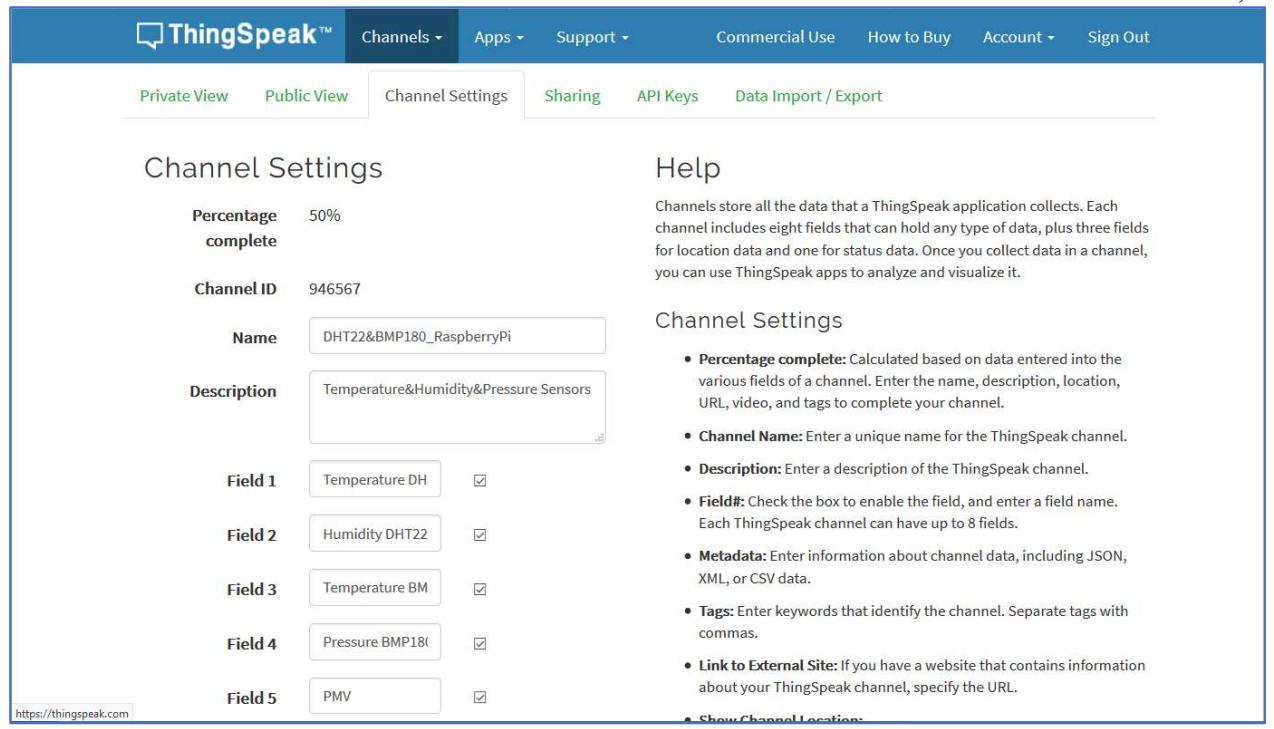

Fig. 2. ThingSpeak configuration: a) Channel details; b) Fields details

A software was developed for the sensor system presented in subchap. 2.1. It is programmed in Python that comes built-in with Raspbian. For this, libraries developed by sensor manufacturers were used and were integrated with the technology made available by ThingSpeak. ThingSpeak not only provides communication through the "GET" and "POST" methods, available in just about any programming language, but in the case of Python it provides a library with methods that can be accessed directly in the code. The result is the publication in the ThingSpeak Channel of the values read by the sensors in the form of graphs corresponding to each Field of the Channel, see fig. 2.

Two libraries, named bmp180 (that is used for BMP180 sensor) and Adafruit_DHT (that is used for DHT22 sensor) are imported. For those libraries, some Raspberry Pi pins number that correspond to sensors pins could be specificity in code. For example, we specified pin GPIO4 on Raspberry Pi board that correspond to data pin of DHT22. For others sensor's pins the default values proposed by libraries are used (and the scheme is constructed according to those default values).

The function that calculates PMV, presented in subchapter 3.2 is called with the parameters read from the sensors. The resulted PMV index is published on another Field of the sensor's Channel. 


\subsection{PMV calculator development}

Using equations (1) to (4) of this paper, the basic computer program given by ISO 7730 [13], and CISBE Guide [16] (Appendix 1.A1: Determination of predicted mean vote (PMV)), a function that calculates the PMV index was developed. It is written in Python software and is added to the software presented in subchapter 3.1.

The signification of the input data in the function are:

clo $=$ Clothing, clo $\left(1 \mathrm{clo}=0.155 \mathrm{~W} / \mathrm{m}^{2} \mathrm{~K}\right)$;

met $=$ Metabolic rate, met $\left(1 \mathrm{met}=58.15 \mathrm{~W} / \mathrm{m}^{2}\right)$, range $\left(58\right.$ to $\left.232 \mathrm{~W} / \mathrm{m}^{2}\right)$;

wme $=$ External work, met;

ta $=$ Air temperature, ${ }^{\circ} \mathrm{C}$;

$\operatorname{tr}=$ Mean radiant temperature, ${ }^{\circ} \mathrm{C}$;

$\mathrm{vel}=$ Relative air velocity, $\mathrm{m} / \mathrm{s}$;

$\mathrm{rh}=$ Relative humidity, $\%$.

The output is PMV.

The partial water vapor pressure, pa, whose formula is not specified in the basic computer program given by ISO 7730 [13], is calculated using equation (5).

$$
p a=r h \cdot e^{\frac{16.6536-4030.183}{t a+235}}
$$

The result must be validated with ISO7730-Table D.1 as requested by the standard. For this validation, a lot of combination of input data imposed by the standard must be used and the result must be compared with the standard values.

The function that calculate PMV index is called with the values imposed by the standard and the results are shown in fig. 3.

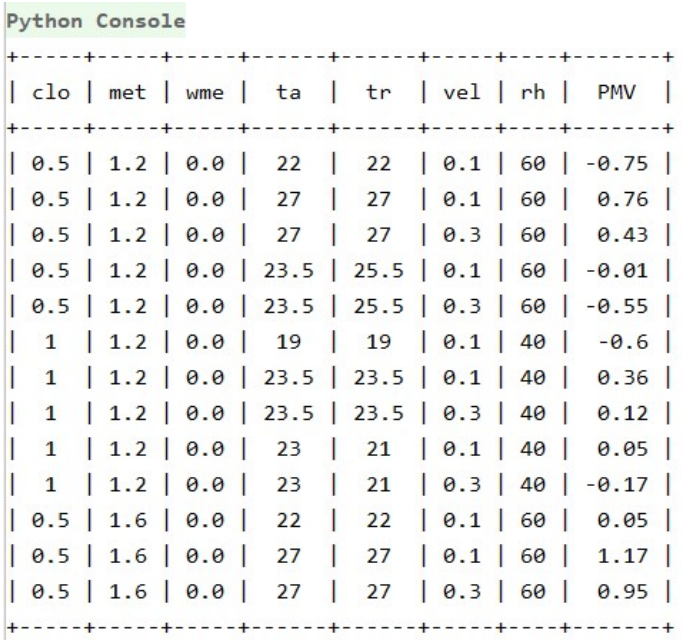

Fig. 3. Result of testing PMV calculator

A comparison of our results with values given standard ISO7730 is presented in table 1. In addition, it is desired to compare with other existing PMV calculators. A study about software applications that compute PMV index is done in [17]. The authors classify them 
according to the environment / operating system (OS) where they are implemented. Thus, there are web applications, Windows or for mobile devices OS. Eight applications have been identified, which is not much around the world. Main input and output parameters for the investigated software are specified.

Besides ISO7730-Table D.1, the output of the new developed software is compared with results obtained from two other PMV calculators: JAVA applet for ISO 7730 [18] and CBE Thermal Comfort Tool [19].

A good correspondence with the ISO7730-Table D.1 values and an almost perfect match with the CBE Thermal Comfort Tool values are remarked. The ISO7730 requirements are met so it can be stated that a PMV calculator has been made in accordance with ISO7730.

Table 1. Validation of the new developed PMV calculator software and comparison with other PMV calculators

\begin{tabular}{|l|l|l|l|}
\hline \multicolumn{5}{|l|}{ PMV value } \\
\hline $\begin{array}{l}\text { ISO7730-Table } \\
\text { D.1 }\end{array}$ & $\begin{array}{l}\text { JAVA applet } \\
\text { for ISO 7730 }\end{array}$ & $\begin{array}{l}\text { CBE Thermal } \\
\text { Comfort Tool }\end{array}$ & $\begin{array}{l}\text { New developed } \\
\text { software }\end{array}$ \\
\hline-0.75 & -0.79 & -0.75 & -0.75 \\
\hline 0.77 & 0.74 & 0.77 & 0.76 \\
\hline 0.44 & 0.42 & 0.43 & 0.43 \\
\hline-0.01 & -0.04 & -0.01 & -0.01 \\
\hline-0.55 & -0.57 & -0.55 & -0.55 \\
\hline-0.6 & -0.63 & -0.6 & -0.6 \\
\hline 0.5 & 0.34 & 0.36 & 0.36 \\
\hline 0.12 & 0.11 & 0.12 & 0.12 \\
\hline 0.05 & 0.02 & 0.05 & 0.05 \\
\hline-0.16 & -0.19 & -0.17 & -0.17 \\
\hline 0.05 & 0.02 & 0.05 & 0.05 \\
\hline 1.17 & 1.16 & 1.17 & 1.17 \\
\hline 0.95 & 0.94 & 0.95 & 0.95 \\
\hline
\end{tabular}

\section{Results and discussion}

As input for PMV calculator some parameters are estimated, some are read from sensors and some are approximated. Usually the level of clothing and metabolism should be approximated in the calculation of PMV.

For the graphics in the fig. 4 we used a value of 0.5 clo for the level of clothing, that means that the clothes are light. Metabolic rate used is $1.2 \mathrm{met}$, it is specific to a standing person with low activity. The air velocity used is approximated with $0.1 \mathrm{~m} / \mathrm{s}$, a low value, suited to open space offices. Any other values could be used as input data.

The air temperature and relative humidity are read by sensors. The mean radiant temperature is considered equal with air temperature, especially in the center of an open plan office, where the influence of outdoor radiant construction elements is very small.

Thus, the input data in the Python program is the following. (The meaning of the terms is presented in subchapter 3.2.)

$$
\text { clo }=0.5
$$


met $=1.2$;

wme $=0.0 ;$

$\mathrm{ta}=$ value given by sensor DTH22;

$\operatorname{tr}=\operatorname{ta} ;$

vel $=0.1$;

$\mathrm{rh}=$ value given by sensor DTH22.

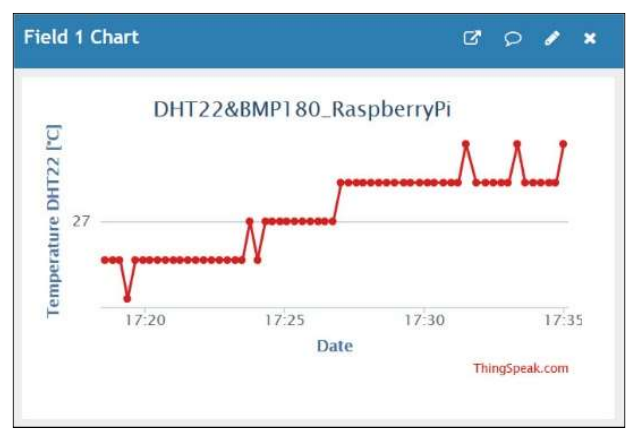

a)

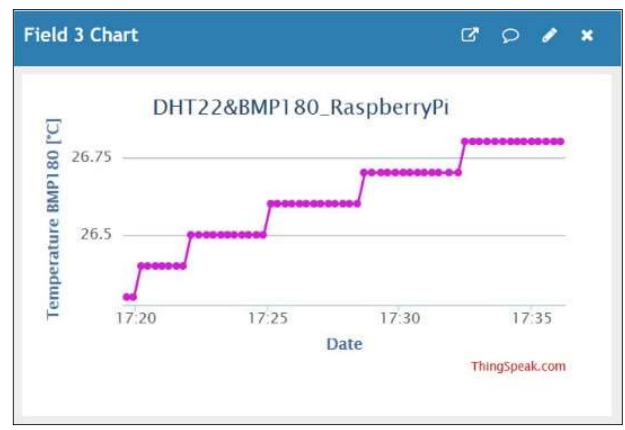

c)

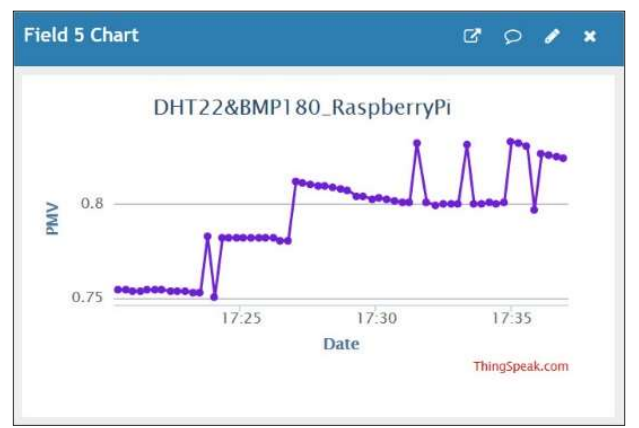

e)

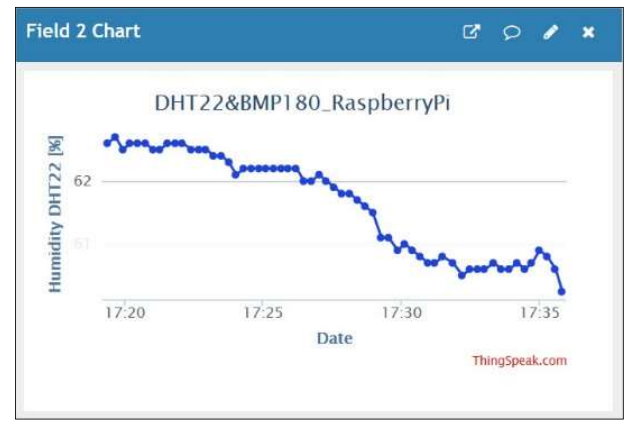

b)

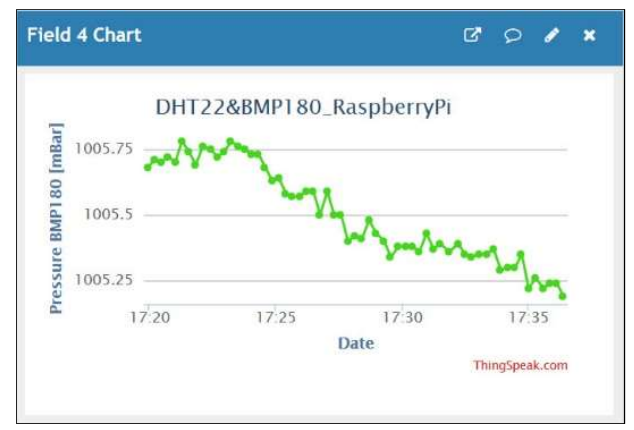

d)

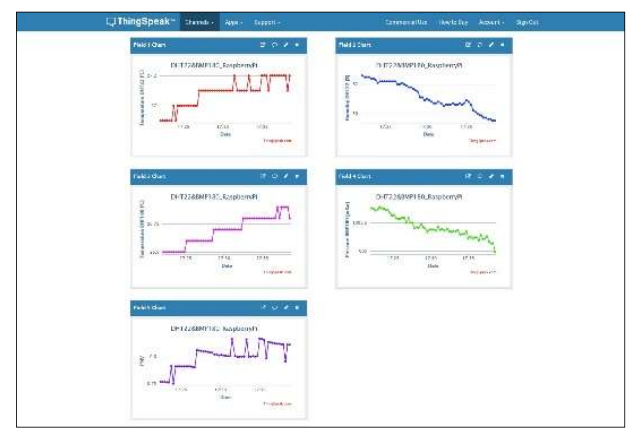

f)

Fig. 4. Charts on ThingSpeak platform: a) Temperature given by DHT22; b) Humidity given by DHT22; c) Temperature given by BMP180; d) Pressure given by BMP180; e) computed PMV; f) "Channels" web page with all charts on it

The graphs in figure 4 represent values measured in a laboratory in an interval of 15 minutes. The data transmission interval to the ThingSpeak platform is 15 seconds. From the graphs in figure 4 we can observe the increasing tendency of the temperature and the decreasing 
tendency of the temperature. It is observed that PMV also has an increasing tendency, it follows the temperature trend but with small variations because the relative humidity also enters in the PMV calculation.

\section{Conclusions}

The PMV calculator software is developed according to ISO 7730 [13] and is validated using the standard validation method. After validation it is used to calculate the PMV having as input data the values read from the sensors and certain estimated values.

The novelty of this paper is the real-time publication, on an IoT platform, of the PMV thermal comfort index. The use of less expensive sensors is considered an advantage, it allows mounting the sensors in countless spaces and the transmission of data in real time. Unlike the performance measuring instruments that must be moved from one area / space of a building to another as the measurements are performed. It should not be forgotten that this system is not regarded as a final measure of the thermal comfort index, it is only an indicator on the places where problems might arise, in those areas teams will be sent to perform high performance measurements.

In addition to the advantage of real-time data transmission, IoT platforms also offer the advantage of centralizing information from multiple locations, a simultaneous tracking of all the spaces in a building, why not the entire portfolio of buildings.

We propose that in further studies we install several such systems in the open space offices of a company or in the halls of a university and to continuously record data over a longer period, of a few weeks, maybe even months. During this period, we also aim to compare the results with measurements made with the ConfortSense device [7] to see what are actually the errors introduced by this solution.

\section{References}

1. J. H. Nord, A. Koohang, J. Paliszkiewicz, The Internet of Things: Review and theoretical framework, Expert Systems With Applications, 133 (2019) 97-108, doi: https://doi.org/10.1016/j.eswa.2019.05.014

2. S. R. Shinde, A. H. Karode and S. R. Suralkar, Review on-IOT Based Environment Monitoring System, International Journal of Electronics and Communication Engineering and Technology, 8(2), 2017, pp. 103-108. http://www.iaeme.com/IJECET/issues.asp?JType=IJECET\&VType=8\&IType $=2$

3. A. Al-Fuqaha, M. Guizani, M. Mohammadi, M. Aledhari and M. Ayyash, "Internet of Things: A Survey on Enabling Technologies, Protocols, and Applications," in IEEE Communications Surveys \& Tutorials, vol. 17, no. 4, pp. 2347-2376, Fourthquarter 2015, doi: 10.1109/COMST.2015.2444095.

4. J. Gubbi, R. Buyya, S. Marusic, and M. Palaniswami, "Internet of Things (IoT): A vision, architectural elements, and future directions," Future Generation Computer Systems, vol. 29, no. 7, pp. 1645-1660, 2013/09/01/ 2013, doi: https://doi.org/10.1016/j.future.2013.01.010.

5. S. Tang, D. R. Shelden, C. M. Eastman, P. Pishdad-Bozorgi, and X. Gao, "A review of building information modeling (BIM) and the internet of things (IoT) devices integration: Present status and future trends," Automation in Construction, vol. 101, pp. 127-139, 2019/05/01/ 2019, doi: https://doi.org/10.1016/j.autcon.2019.01.020.

6. Fanger P.O (1970), Thermal Comfort. Analysis and Applications in Environmental Engineering. Published in the United States by McGraw-Hill Book Company 1972. Originally presented as the author's thesis, Danmarks Teknishe Højskole 1970 
7. ComfortSense, measurement system, developed by Dantec Dynamics, https://www.dantecdynamics.com/solutions-applications/solutions/thermalcomfort/comfortsense/, (accessed Mai 2020)

8. I. Udrea, V. Badescu, Usage of solar shading devices to improve the thermal comfort in summer in a Romanian PassivHaus, Simulation: Transactions of the Society for Modeling and Simulation International 1-16, (2019), DOI: 10.1177/0037549719887790

9. DHT 22, temperature-humidity sensor, https://www.adafruit.com/product/385, (accessed March 2020)

10. BMP180, Barometric Pressure/Temperature/Altitude Sensor, https://www.adafruit.com/product/1603, (accessed March 2020)

11. Raspberry Pi4, desktop computer, https://www.raspberrypi.org/products/raspberry-pi-4model-b/, (accessed March 2020)ThingSpeak (2020), IoT Analytics Platform, https://thingspeak.com/, (accessed March 2020)

12. ThingSpeak (2020), IoT Analytics Platform, https://thingspeak.com/, (accessed March 2020)

13. ISO-7330, (2005), International Standard ISO 7330: Ergonomic of the thermal environment - Analytical determination and interpretation of thermal comfort using calculation of the PMV and PPD indices and local thermal comfort criteria.

14. Webb, A. L. (2012), Mapping Comfort: An Analysis Method for Understanding Diversity in the Thermal Environment, Master in Science in Architecture Studies at the Massachusetts Institute of Technology

15. Raspbian (2020), official supported operating system for Raspberry Pi, https://www.raspberrypi.org/downloads/raspbian/, (accessed March 2020)

16. Environmental design, CIBSE Guide A, The Chartered Institution of Building Services Engineers London, The Yale Press Ltd, Norwood, London SE25 5LY, ISBN 0900953 96 9, (1999)- Carte, unde in cap Appendix 1.A1: Determination of predicted mean vote (PMV) am gasit programul recomandat de ISO 7730 reformulat si cu greseli corectate.

17. F.R.A. Alfano, B. I. Palella, G. Riccio, Notes on the Calculation of the PMV index by means of Apps, 71st Conference of the Italian Thermal Machines Engineering Association, ATI2016, 14-16 September 2016, Turin, Italy, published in Energy Procedia 101 ( 2016 ) $249-256$ (2016)

18. JAVA applet for ISO 7730, ISO 7730 Ergonomics of the thermal environment. Analytical determination and interpretation of thermal comfort using calculation of the PMV and PPD indices and local thermal comfort, PMV 2008 ver. 1.0, Ingvar Holmer, http://www.eat.lth.se/fileadmin/eat/Termisk_miljoe/PMV-PPD.html, (accessed March 2020)

19. T. Hoyt, S. Schiavon, F. Tartarini, T. Cheung, K. Steinfeld, A. Piccioli, and D. Moon, 2019, CBE Thermal Comfort Tool. Center for the Built Environment, University of California Berkeley, https://comfort.cbe.berkeley.edu/EN, (accessed March 2020) 